Trakya Ĕ̈itim Dergisi

Cilt 9, Sayı 1

Ocak 2019, 32-43

Gelis Tarihi: 15.03.2018

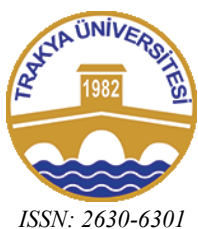

Doi: $10.24315 /$ trkefd. 406400
Trakya Journal of Education

Volume 9, Issue 1

January 2019, 32-43

Araştırma Makalesi

\title{
Mobil Öğrenme: 2010-2017 Çalışmalarına Yönelik Bir İçerik Analizi
}

\section{Mobile Learning: A Content Analysis for 2010-2017 National Studies}

\section{Agâh Tuğrul KORUCU ${ }^{1}$, Hüsniye BİÇER ${ }^{2}$}

\begin{abstract}
Öz: Mobil cihazların giderek gelişmesi ve yaygınlaşması eğitim alanını da etkilemiştir. 2010-2017 yılları arasında, 2017 yılının ocak, şubat ve mart ayları ele alınarak, yayınlanmış Türkiye adresli mobil öğrenme üzerine yapılan araştırmaların tanımlayıcı özelliklerini, yöntemsel boyutlarını ve genel eğilimlerini ortaya çıkarmayı amaçlayan bu çalışma Google Scholar, Academia.edu ve Dergipark adresleri üzerinde aranmış, dergilerde yayımlanan makalelerden oluşan toplam 24 mobil öğrenme çalışması ile gerçekleştirilmiştir. Verileri toplamada Sözbilir, Kutu ve Yaşar (2012) tarafindan geliştirilmiş olan yayın sınıflama formu mobil öğrenme konularına uygun olarak revize edilerek kullanılmıștır. Sonuç olarak kullanılan çalışmalar içerisinde en çok yayının Eğitim Teknolojisi Kuram ve Uygulama dergisinde yayınlandığı, araştırma konularının en çok mobil öğrenme hakkında değerlendirme yapma üzerine olduğu, bu çalışmalarda en çok nitel yöntemin kullanıldığı, veri toplama aracı olarak en s1k kullanılanların anket, görüşme ve gözlem olduğu, en sık kullanılan örneklem düzeyinin eğitim fakültesinde okuyan lisans öğrencilerinin oluşturduğu, en yaygın olarak kullanılan örneklem aralığının ise 11-30 olduğu bulgularına ulaşılmıştır.
\end{abstract}

Anahtar sözcükler: m-öğrenme, içerik analizi, 2010-2017.

\begin{abstract}
The development and widespread use of mobile devices has also affected the field of education. This study aims to reveal the descriptive characteristics, methodological dimensions and general trends of research on mobile learning in Turkey published between the first 3 months of 2010 and 2017. This study includes 24 mobile learning studies consisting of articles published in Google Scholar, Academia.edu and Dergipark. The data in total were revised and used in accordance with the mobile learning topics of the publication classification form developed by Sözbilir, Kutu and Yaşar (2012). As a result, the following facts were revealed; the most frequently used data collection tools were survey, interview and observation, the most frequently used data were published in the Journal of Educational Technology Theory and Practice, the research topics were mostly on evaluating mobile learning, the most commonly used sample level was found by under-graduate students studying at the education faculty, and the most commonly used sample range was 11-30.
\end{abstract}

Keywords: m-learning, content analysis, 2010-2017

Cite this article as:

Esen Aygün, H., \& Şahin Taşkın, Ç. (2019). Öğretmen adaylarının üniversite yaşamına sosyal, kişisel ve akademik uyumları. Trakya Eğitim Dergisi, 9(1): 32-43.

\section{EXTENDED ABSTRACT}

\section{Introduction}

Technological developments which have succeeded to be included in every field of life have created new learning and teaching processes and have played a supporting role in enabling new understanding and entry of new concepts into the field of education and different materials and different environments with features that can provide flexibility for users independent of time and place in educational processes. In this context, electronic learning (e-learning) has taken its place in education as the most important learning and learning environment, with the expansion of personal computers and the Internet that can provide flexibility. But as the days go by, some features of e-learning have begun to be presented as insufficient and restrictive in terms of providing full flexibility. This lack of mobile devices has begun to reveal ideas that can be removed. In this context, it is considered that the examination of studies on mobile technologies which are becoming increasingly widespread and increasing in use will be important in terms of future research.

\footnotetext{
${ }^{1}$ Dr. Öğr. Üyesi, Necmettin Erbakan Üniversitesi, akorucu@konya.edu.tr

${ }^{2}$ Yüksek Lisans Öğrencisi, Necmettin Erbakan Üniversitesi, hsnybcr@gmail.com
} 


\section{Method}

Considering this importance, this study which is composed of 24 mobile learning studies consisting of articles published in the magazines, which were searched with the keyword of mobile learning on Google Scholar, Academia.edu and Dergipark addresses of Turkey between 2010 and 2017, aims to reveal the general tendencies, the descriptive characteristics and methodological dimensions of these researches. Content analysis method was used for the analysis of the research. The publication classification form developed by Sözbilir, Kutu and Yaşar (2012) was used by the researchers to review the collected articles in order to examine the collected articles. The data obtained by using the form were analysed by using percent and frequency values.

\section{Results and Discussion}

As a result, it has been found that most of the 24 publications published in 15 magazines were published in the Journal of Educational Technology Theory and Practice, Academic Information Conferences, Open Education Practices and Researches between 2015 and 2016. The topics of these studies are among other findings that focus on mobile learning, studies on what mobile learning technologies are, and project development work on mobile learning. Considering the methods used in the studies, it is observed that most qualitative methods are used and the methods based on mobile learning are used in the evaluation studies on mobile learning. Most studies on mobile learning technologies use the most qualitative method. In the field of development studies on mobile learning, the most frequent qualitative method was used. The most commonly used tools as data collection tools are articles and developed mobile learning platforms, and interviews and observations are among the results that follow this frequency. When considering the data collection tools used according to the research method, it is determined that the most used method in quantitative research method is questionnaire, the most used methods in qualitative research method are articles and developed mobile learning platforms, the most used methods in mixed method are questionnaire and interview and the most used methods in literature compilation method are articles and developed mobile learning platforms. In the study, most articles, platforms developed for mobile learning and students studying at vocational school were selected as sample level. It is observed that the most frequently used sample interval range is between 11-30. When the methods and intervals used are compared, it is found that the most used ranges are the following; 301-1000 in the studies using quantitative research method, 11-30 in the studies using qualitative research method, 31-100 and 101-300 in mixed method, and 1-10, 1130, 31-100 in literature compilation. It is suggested that the findings obtained in the study will be important in terms of contributing to future research and it is suggested that the study should be expanded and examined by considering different dimensions by taking different samples.

\section{GİRIŞ}

İçinde bulunduğumuz ve bilgi çağı olarak adlandırılan çağımızda, gelişim ve değişim süreçleri hızlı bir şekilde gerçekleşmektedir. Hızla yayılan bu süreçte insanların bilgi üretmesi, bilgiye erişmesi, bilgiyi yayması, bilgileri deneyimleyerek hayata uyarlamaları aşamalarında zamanla yarışılması kaçınılmaz bir durum oluşmuştur. Hızla devam eden bu gelişim ve değişimlere ayak uydurmak için yaşamın her alanında zamandan tasarruf ederek az zamanda çok iş başarmak ise içinde bulunduğumuz çağda bir zorunluluk haline gelmiştir. Nitekim Bal (2010) yaşam hızının artması ile birlikte insanların kısa bilgiye erişme ve deneyim kazanmaları için gerekli olan süreyi kısaltmalarının bir ihtiyaç hatta bir zorunluluk olduğunu ifade etmiştir.

Teknolojinin gelişmesi ile hızlanan bu çağda, çağın gerekliliklerine ayak uydurma ve bu hıza ulaşma yolunda, insanlara yaşamın her alanında firsatlar sunmada yine teknolojik cihazlar etkili olmuştur. Hayatımızın her alanı bu teknolojik gelişmelerden etkilenmiş ve bu gelişmeler hayatımızda sağlık, eğitim, siyasal, sosyal gibi tüm alanlarda yerini almayı başarmıştır. Kuşkonmaz (2011) teknolojinin kapsamının insan yaşamı ile ilgili faaliyetlerin tümü olduğunu ifade etmiştir. Yani insanın bulunduğu her ortamda ve insanların yaşamının her alanında teknoloji kullanımı ve teknolojik etkinliklerin mevcut olduğu söylenebilir. Bu anlamda yaşamın her alanında yer almayı başaran teknolojik gelişmeler, insan faaliyetlerinin en önemlilerinden biri olan eğitim alanında da yeni öğrenmeöğretme süreçleri oluşturmuş yeni anlayış ve yeni kavramların eğitim alanına girmesini sağlamıştır. $\mathrm{Bu}$ durum eğitim ve öğretim alanında farklı materyaller ve farklı ortamların gelişmesi ve desteklenmesi sürecinde yardımcı bir rol üstlenmiştir. Geçmişte sadece yazılı kaynaklar kullanılarak yürütülen 
öğrenme-öğretme süreçleri zamanla sesli, görüntülü, etkileşimli gibi çoklu ortam unsurları sunan çeşitli materyaller ile desteklenmeye ve gelişmeye başlamıştır. Gelişen ve değişen bu materyallerle birlikte bu materyallerin kullanılabileceği farklı ortamlar da oluşturulmaya başlamıştır. Nitekim Korkmaz (2010) da öğrenme-öğretme süreçleri için farklı yöntem ve araçların geliştirildiği, bu araçların kullanımı için ise uygun ortamların meydana geldiğini ifade etmiştir. Bu süreçlerde kullanılan araçlar ve bu araçların kullanıldığı ortamlar açısından bakıldığında özellikle kişisel bilgisayarların yaygınlaşması ile birlikte hayatımıza giren "İnternet" eğitim alanını etkileyen en önemli araç, bilgisayar ve İnternet kavramları ile gelişerek eğitim alanına giren "elektronik öğrenme (e-öğrenme)" ise en önemli öğrenme-öğretme ortamı olarak eğitimdeki yerini almıştır.

E-öğrenme, kısaca teknoloji ve eğitimin bir arada kullanılması olarak tanımlanabilir (Siemens, 2002). Daha detaylı bir şekilde ifade edilecek olursa e-öğrenme; İnternet, İntranet veya bir bilgisayar ağı bulunan platform üzerinden gerçekleştirilen, öğretmen ve öğrencinin aynı ortamda ve aynı anda bulunmalarına gerek kalmadan sunulan web tabanlı eğitim faaliyetleridir (Akpınar, 2005; Özarslan, vd., 2007). E-öğrenmeye yönelik alanyazın incelendiğinde ve yapılan tanımlara bakıldığında e-öğrenmenin zaman ve mekandan bağımsız olma özelliği ile dikkat çektiği ve zaman-mekandan bağımsız olma özelliğinin sık s1k vurgulandığı gözükmektedir. Fakat gün geçtikçe e-öğrenmenin zaman ve mekan açısından esneklik sağladığı lakin her zaman ve her yerde öğrenme için yetersiz ve kısıtlayıcı olduğu fikirleri sunulmaya başladığı fikirleri de gözükmektedir. Bu anlamda Yılmaz (2011), e-öğrenmenin bir yerde bilgisayar başında olma zorunluluğundan dolayı yeterli olmadığı görüşlerinin ortaya çıktığını ifade ederek e-öğrenmenin eksik kalan noktalarına dikkat çekmiştir.

Son yıllarda hızla gelişen ve yaygınlaşan teknolojiler bu eksiklikleri giderme konusunda da kendini göstermiş, akıllı telefon, tablet gibi taşınabilir cihazlar bilgisayarların gösterdikleri performans1 karşılamaya başlamıştır. Yüksek performansa sahip olmaları, kullanıcıya zaman, mekan gibi farklı değişkenler açısından daha esnek bir kullanım sağlamaları gibi özellikler barındırmaları eğitim alanında e-öğrenme konusunda eksik kalan noktaların mobil cihazlar ile desteklenmesini sağlamıştır. $\mathrm{Bu}$ cihazların eğitimde kullanımının yaygınlaşması ise mobil öğrenme (m-öğrenme) kavramını oluşturmuştur. M-öğrenme, zamandan ve mekândan bağımsız olarak e-öğrenme içeriğine erişilebilen ve iletişim sağlayan, e-öğrenme ve uzaktan eğitim alanlarının ortak bir sonucu olarak ortaya çıkan öğrenme şeklidir (Raua vd., 2008). M-öğrenme, e-öğrenmenin bir uzantısı olarak ele alınmakla birlikte alanyazın tarandığında m-öğrenmenin e-öğrenmeyi kapsadığı birçok tanıma ulaşmak mümkündür (Quinn, 2000; Hahn, 2008; Parsons \& Ryu, 2006; Winters, 2007). M-öğrenmenin e-öğrenmeyi kapsadığı fakat zaman ve yer kısıtlamasını ortadan kaldırarak her zaman her yerde öğrenim sunması açısından e-öğrenmeden farklılaştığı da gözden kaçırılmaması gereken bir noktadır. Nitekim Bal ve Arıcı (2011) da e-öğrenmede masaüstü bilgisayarlar ve sabit hat İnternet bağlantısına ihtiyaç duyulurken mobil cihazlar bu sabit unsurlara olan bağımlılığı ortadan kaldırdığını ifade ederek bu farka dikkat çekmiştir. Alanyazına bakıldığında birçok çalışmada m-öğrenmede kullanılabilecek cihazlara, bu cihazların özelliklerine, tercih edilme sebeplerine, eğitimde sağladıkları katkılar gibi içeriklere dikkat çekildiği gözükmektedir.

Bu çalışmalar ele alındığında m-öğrenme süreçlerini gerçekleştirmek için en çok kullanılabilecek olan cihazların şu şekilde sıralandığı gözükmektedir; dizüstü bilgisayarlar, tablet bilgisayarlar, giyilebilir bilgisayarlar, cep bilgisayarları, netbook, cep telefonları, akıllı cep telefonları, kişisel dijital asistan, taşınabilir mp3 player, ipad, ipod touch, taşınabilir oyun araçları, usb bellekler, avuç içi cihazlar (Winters, 2006, 4; Niazi, 2007; Yılmaz, 2011; Wyne, 2015; Yokuş, 2016). Bu cihazların özellikleri incelendiğinde ise bir hücresel/kablosuz ağa bağlı olan ama güç kaynağı gibi bir yere bağlı olmayan, her zaman kullanılabilir, kesintisiz iletişim olanağı sağlayan, kullanıcıya tamamen bağımsızlık ve özgürlük tanıyan, dinamik, hızlı, esnek, pratik, kişisel, özel, daha küçük ve hafif olmaları ile taşınabilirlik kazanan portatif cihazlar olması gibi bir takım ortak özellikleri dikkat çekmektedir. Kullanıcıya birçok firsat ve olanak sunan tüm bu özelliklere sahip cihazlarla sağlanacak olan möğrenme; öğrenci merkezli olarak bireysel öğrenme gereksinimlere hemen cevap verecek hedef ve motivasyonu destekleyerek ihtiyaçları karşılayacak, öğrenme esnasında etkileşim ve işbirliği sağlayarak çevrimiçi topluluk hissini, performansını, üretkenliğini destekleyerek ve artırarak kalıcı öğrenmeyi sağlayacak, geleneksel öğrenme ortamlarından farklı bir öğrenme ortamı sunacaktır. Ayrıca m-öğrenme ve m-öğrenmeyi gerçekleştirecek cihazlar için; yenilikleri izleyerek, beklerken zamanı 
etkili ve verimli kullanarak soruları hızlı bir şekilde cevaplayıp öğrenmeyi sürdürecek olmaları gibi çeşitli yararları olduğu da belirtilmiştir (Güneş, vd., 2015). Ayrıca, mobil teknolojilerin eğitim için destekleyici bir araç, imkansızlıklara çözüm getirecek bir yapı ve güç olduğu belirtilmiş, m-öğrenmenin bilgi erişimini artırarak, engeli bulunan öğrencileri desteklemesi, firsat eşitliği sağlaması ve eğitim kesintilerini en aza indirmesi, sınıflarda harcanan zamanın verimini artırması, iletişim ve yönetimi geliştirerek, formal ve informal öğrenme arasında bağ kurarak maliyet verimliliğini en üst düzeye çıarması gibi sonuçların saptandığını belirtilmiştir (UNESCO'dan aktaran Güneş vd., 2015).

Mobil cihazların tüm bu özellikleri, giderek yaygınlaşması, kullanımının artması ve kullanıcı kitlesi gibi etmenler göz önüne alındığında mobil cihazların hayatın her alanında etkisini sürdüreceği kaçınılmaz gözükmektedir. Hayatımızda birçok alanda etkili olmayı başarmış mobil cihazların eğitimde kullanılarak nasıl daha iyi hale getireceği de önemli bir araştırma konusu olmuştur (Trifonova, 2003). Hayatımızın her alanında kullanımı bu kadar artan teknolojilerin eğitim alanında da etkisini göstereceğine inanılmaktadır. Nitekim mobil çağ geleceği oluşturacaksa, geleceğin öğrenme biçimi de m-öğrenme olabilir (Yılmaz, 2011). Bu anlamda giderek önemi artan m-öğrenme üzerinde yapılan çalışmaların çeşitli değişkenler ele alınarak incelenmesinin yapılan çalışmaların ne doğrultuda ilerlediğinin ortak bir çerçeve altında görülebilmesi, alanda varsa eksik kalan yönlerin belirlenebilmesi, $\mathrm{m}$-öğrenme konusunda hangi alt temalara değinildiği hakkında fikir edinilebilmesi açısından önemli olacağı düşünülmektedir. $\mathrm{Bu}$ araştırmada m-öğrenme üzerine yapılan çalışmaların incelenmesinin gelecekte yapılacak araştırmalara yön göstermesi, m-öğrenme süreçlerinin daha etkili ve verimli tasarlanması, planlanması ve uygulanmasında fikir sunması açısından da önemli olacağı düşünülmektedir. Bu önem doğrultusunda yola çıkılarak bu araştırma kapsamında 2010-2017 yılının Ocak, Şubat ve Mart ayları arasında yayınlanmış Türkiye adresli m-öğrenme üzerine yapılan araştırmaların tanımlayıcı özelliklerini, yöntemsel boyutlarını ve genel eğilimlerini ortaya çıkarmak amaçlanmaktadır. $\mathrm{Bu}$ amaç kapsamında, bu araştırmada aşağıdaki sorulara cevap aranmıştır:

M-öğrenme üzerine yapılan araştırmalar yaygın olarak;

1. Hangi dergilerde yayınlanmıştır?

2. Hangi araştırma konuları tercih edilmiştir ve bunların yıllara göre dağılımı nasıldır?

3. Hangi yöntemler kullanılmıştır ve bunların konulara göre dağılımı nasıldır?

4. Hangi veri toplama araçları kullanılmıştır ve bunların yöntemlere göre dağılımı nasıldır?

5. Örneklem özellikleri nasıl değişmektedir?

5.1. Hangi örneklem düzeyleri tercih edilmiştir?

5.2. Örneklem büyüklükleri hangi aralıklardadır?

\section{1.Çalışmanın Yöntemi ve Çalışma Grubu}

\section{YÖNTEM}

Bu çalışmada 2010-2017 yılları arasında Türkiye adresli olan çeşitli dergilerde yayınlanmış möğrenme üzerine yapılan araştırmalar içerik analizi yöntemi temel alınarak incelenmiştir. İçerik analizi, çeşitli kaynaklar kullanılarak birbirine benzer nitel verilerin, belirli bir tema ve kavram çerçevesinde bir araya getirilip nicel analizler yapılması ve bu verilerden anlam çıkartıp okurların anlayabileceği şekilde düzenlenmesi ve yorumlanmasıdır (Bauer, 2003; Yıldırım ve Şimşek, 2006; Salanda, 2011). İçerik analizi, nitel veri analiz türleri arasında en sık kullanılan yöntemlerden biri olup tümdengelimci yol takip edilerek, ağırlıklı olarak yazılı ve görsel verilerin analiz edilmesinde kullanılan bir yöntemdir. $\mathrm{Bu}$ yöntemde araştırmacı dikkatli bir şekilde ve başka araştırmacıların anlayabileceği şekilde araştırma konusu ile ilgili kategoriler geliştirip, bu kategoriler içerisinde bulunan kelime, cümle ya da resimleri saymakta, düzenleyip yorumlamaktadır (Silverman, 2001).

$\mathrm{Bu}$ çalışmada her ağdan rahatlıkla ulaşılabilecek Google Scholar, Academia.edu ve Dergipark adresleri üzerinde mobil öğrenme, mobil cihazlar ve eğitimde mobil öğrenme anahtar kelimeleri ile arama yapılmıştır. $\mathrm{Bu}$ anahtar kelimeler ile yapılan arama sonucunda 45 araştırmaya ulaşılmıştır. $\mathrm{Bu}$ araştırmalar incelenmiş ve özet bildiri olan, Türkçe dilinde yazılmayan, 2010 yılından önce yapılmış olan veya içeriğine bakıldığında m-öğrenmeyi desteklemeyen araştırmalar elenmiştir.

Sonuç olarak 2010-2017 yılının Ocak, Şubat ve Mart aylarını kapsayan m-öğrenme içeriğine sahip, özet bildiri şeklinde olmayan ve Türkçe dilinde yazılmış elde edilen toplam 24 m-öğrenme çalışması bu çalışmanın örneklemini meydana getirmiştir. 


\subsection{Veri Toplama Aracı}

Elde edilen makaleleri belli özelliklere göre sınıflayabilmek için Sözbilir, Kutu ve Yaşar (2012) tarafından geliştirilmiş olan yayın sınıflama formu m-öğrenme araştırmaları için araştırmacılar tarafından düzenlenerek kullanılmıştır. Yayın sınıflama formu 6 bölümden oluşmaktadır ve şu başlıkları içermektedir: Makalenin künyesi, makalenin türü, makalenin konusu, makalenin yöntemi, veri toplama araçları ve örneklemdir. Bu başlıklar ele alınarak Microsoft Excel programında tablo oluşturulmuş ve makaleler türleri, konuları, yöntemleri, veri toplama araçları ve örneklemlerine göre ayrılmıştır.

\subsection{Verilerin Analizi}

Yayın sinıflama formu kullanılarak elde edilen veriler, Microsoft Excel programı kullanılarak, her bir araştırma sorusunun cevabına karşıllk gelecek şekilde girilmiştir. Veriler içerik analizi kullanılarak incelenmiş, yüzde ve frekans değerleri kullanılarak çözümlenmiştir. Elde edilen verilerin frekansları ve yüzde oranları hesaplanarak sonuçlar tablo haline getirilmiştir. Tablo haline getirilen sonuçlar bulgular kısmında verilmiş ve yorumlanmıştır.

\section{BULGULAR}

Elde edilen makalelerden toplanan veriler araştırma soruları dikkate alınarak analiz edilmiştir. Analiz sonucunda elde edilen bulgular aşağıda sunulmuştur. Araştırmada yer alan çalışmaların hangi dergilerde yoğun olarak yayınladığına dair sonuçlar Tablo 1'de verilmiştir.

Tablo 1. Mobil öğrenme araştırmalarının yer aldığı dergiler

\begin{tabular}{lcc} 
DERGINiN ADI & ARAŞTIRMA & YÜZDE \\
\hline Eğitim Teknolojisi Kuram ve Uygulama & 3 & 12,5 \\
Akademik Bilişim Konferansı & 3 & 12,5 \\
Açı̈öğretim Uygulamaları ve Araştırmaları Dergisi & 3 & 12,5 \\
Bartın Üniversitesi Eğitim Fakültesi Dergisi & 2 & 8,3 \\
Eğitim ve Öğretim Araştırmaları Dergisi & 2 & 8,3 \\
Sakarya Üniversitesi Eğitim Fakültesi Dergisi & 1 & 4,2 \\
Bilişim Teknolojileri Dergisi & 1 & 4,2 \\
Adnan Menderes Üniversitesi Eğitim Fakültesi Eğitim Bilimleri Dergisi & 1 & 4,2 \\
Sınırsız Ĕ̆itim ve Araştırma Dergisi & 1 & 4,2 \\
Ege Eğitim Dergisi & 1 & 4,2 \\
Eğitim Yönetimi Forumu & 1 & 4,2 \\
International Journal of Social Sciences and Education Research & 1 & 4,2 \\
International Computer and Instructional Technologies Symposium & 1 & 4,2 \\
International Conference on New Trends in Education and Their Implications & 1 & 4,2 \\
Belirtilmemiş & 2 & 8,3 \\
\hline TOPLAM & $\mathbf{2 4}$ & $\mathbf{1 0 0}$ \\
\hline
\end{tabular}

Araştırmada 15 dergide yayımlanmış olan 24 çalışma incelenmiştir. İncelemeler sonucunda Tablo 1'de ki sonuçlar elde edilmiştir. Tablo 1 incelendiğinde $\mathrm{m}$ - öğrenme üzerine yapılan araştırmaların en çok Eğitim Teknolojisi Kuram ve Uygulama Dergisi, Akademik Bilişim Konferansları, Açıköğretim Uygulamaları ve Araştırmaları Dergisinde yayınlandığı gözükmektedir. Bu dergileri Bartın Üniversitesi Eğitim Fakültesi Dergisi, Eğitim ve Öğretim Araştırmaları Dergisi takip etmiş ve diğer dergilerin de m-öğrenme üzerine yapılan çalışmalara yer verdiği sonuçlarına ulaşılmıştır. Tabloda yer alan belirtilmemiş seçeneğinde ise, makalenin çevrimiçi bir araştırma sitesinde yayınlandığı görülmüştür. Bu araştırma herhangi bir dergide yer almadığı ve sadece bir İnternet sitesinde yer aldığı için belirtilmemiş olarak isimlendirilmiştir.

Araştırmada yer alan çalışmaların konularının yıllara göre dağılımları Tablo 2'de gösterilmiştir. 
Tablo 2. Mobil öğrenme araştırmalarının konularının yıllara göre dağılımı

\begin{tabular}{|c|c|c|c|c|c|c|c|c|c|c|c|}
\hline \multirow{2}{*}{ Çalışmanın Konusu } & \multicolumn{9}{|c|}{ Yillar } & \multicolumn{2}{|c|}{ TOPLAM } \\
\hline & 2010 & 2011 & 2012 & 2013 & 2014 & 2015 & 2016 & 2017 & Belirtilmemiş & $\mathbf{N}$ & $\%$ \\
\hline $\begin{array}{l}\text { M-Öğrenme Hakkında } \\
\text { Görüşler }\end{array}$ & & & & 1 & & & 1 & & & 2 & 8,3 \\
\hline $\begin{array}{l}\text { M-Öğrenme } \\
\text { Teknolojileri }\end{array}$ & 2 & 1 & & & & & 1 & & & 4 & 16,7 \\
\hline $\begin{array}{l}\text { M-Öğrenme Proje } \\
\text { Çalışması }\end{array}$ & & 1 & & & & 1 & & & 2 & 4 & 16,7 \\
\hline $\begin{array}{l}\text { M-Öğrenme Üzerine } \\
\text { Değerlendirme }\end{array}$ & & & & & & 3 & 1 & 1 & & 5 & 20,8 \\
\hline $\begin{array}{l}\text { M- Öğrenme İçerik } \\
\text { Analizi } \\
\text { M-Öğrenmeye }\end{array}$ & & & 1 & & & & 1 & & & 2 & 8,3 \\
\hline Yönelik Ölçek & & & & 1 & & & 1 & 1 & & & \\
\hline $\begin{array}{l}\text { Çalıšması } \\
\text { M-Öğrenmeye }\end{array}$ & & & & & & & & & & 3 & 12,5 \\
\hline Yönelik Tutum & & & & & & 1 & & & 1 & & \\
\hline Belirleme & & & & & & & & & & 2 & 8,3 \\
\hline $\begin{array}{l}\text { M-Ögrenmeye } \\
\text { Yönelik beklenti } \\
\text { M-Öğrenmenin }\end{array}$ & 1 & & & & & & & & & 1 & 4,2 \\
\hline $\begin{array}{l}\text { M-Ogrenmenin } \\
\text { Beceriye Etkisi }\end{array}$ & & & & & & 1 & & & & 1 & 4,2 \\
\hline TOPLAM & 3 & 2 & 1 & 2 & $\mathbf{0}$ & 6 & 5 & 2 & 3 & 24 & 100 \\
\hline
\end{tabular}

Tablo 2'ye bakıldığında yapılan çalışmalarda m-öğrenme üzerine değerlendirme yapma, möğrenme teknolojilerinin neler olduğu üzerine yapılan çalışmalar ve m-öğrenme üzerine proje geliştirme çalışmaları üzerine yoğunlaşılmış olduğu gözükmektedir. M-öğrenmeye yönelik tutumu, beklentiyi ve m-öğrenmenin bazı becerilere olan etkisi üzerine yapılan çalışmaların az olduğu görülmektedir. Tablo 2 yıllara göre incelendiğinde ise en çok çalışmanın 2015, 2016 yılları arasında gerçekleştirildiği 2014 yılında ise herhangi bir çalışmaya rastlanılmadığı sonuçları elde edilmektedir. Ayrıca m-öğrenme üzerine değerlendirme çalışmalarının en çok 2015 yılında gerçekleştirildiği, möğrenme teknolojileri üzerine yapılan çalışmaların ise en çok 2010 yılında gerçekleştirildiği diğer bulgular arasindadır.

Araştırmada yer alan çalışma yöntemlerinin konulara göre dağılımına yönelik sonuçlar Tablo 3 'te gösterilmiştir.

Tablo 3. Mobil öğrenme araştırmalarının çalışma yöntemlerinin konulara göre dağglımı

\begin{tabular}{|c|c|c|c|c|c|c|c|c|c|c|c|}
\hline \multirow[b]{2}{*}{ Yöntem } & \multicolumn{9}{|c|}{ Çalışmanın Konusu } & \multicolumn{2}{|c|}{ TOPLAM } \\
\hline & $\begin{array}{l}\text { M-Öğrenme } \\
\text { Hakkında } \\
\text { Görüsşler }\end{array}$ & $\begin{array}{l}\text { M-Öğrenme } \\
\text { Teknolojileri }\end{array}$ & $\begin{array}{c}\text { M- } \\
\text { Öğrenme } \\
\text { Proje } \\
\text { Çalı̧̧ması }\end{array}$ & $\begin{array}{l}\text { M- } \\
\text { Öğrenme } \\
\text { Üzerine } \\
\text { Değerlend } \\
\text { irme }\end{array}$ & $\begin{array}{c}\text { M- } \\
\text { Öğrenme } \\
\text { İcerik } \\
\text { Analizi }\end{array}$ & $\begin{array}{c}\text { M- } \\
\text { Öğrenm } \\
\text { eye } \\
\text { Yönelik } \\
\text { Ölçek } \\
\text { Çalşsma } \\
\text { s1 }\end{array}$ & $\begin{array}{c}\text { M- } \\
\text { Öğrenmey } \\
\text { e Yönelik } \\
\text { Tutum } \\
\text { Belirleme }\end{array}$ & $\begin{array}{c}\text { M- } \\
\text { Öğrenmey } \\
\text { e Yönelik } \\
\text { Beklenti }\end{array}$ & $\begin{array}{c}\mathrm{M}- \\
\text { Öğrenme } \\
\text { nin } \\
\text { Beceriye } \\
\text { Etkisi }\end{array}$ & $\mathbf{N}$ & $\%$ \\
\hline Nicel & & & & & 1 & 3 & 2 & 1 & 1 & 8 & 33,3 \\
\hline Nitel & 1 & 1 & 3 & 4 & 1 & & & & & 10 & 41,7 \\
\hline Karma & 1 & & 1 & & & & & & & 2 & 8,3 \\
\hline $\begin{array}{l}\text { Alan Yazın } \\
\text { Derl. }\end{array}$ & & 3 & & 1 & & & & & & 4 & 16,7 \\
\hline TOPLAM & 2 & 4 & 4 & 5 & 2 & 3 & 2 & 1 & 1 & 24 & 100 \\
\hline
\end{tabular}


Tablo 3 incelendiğinde m-öğrenme üzerine yapılan çalışmalarda ağırlıklı olarak nitel yöntemin ve onu takip eden nicel yöntemin kullanıldığı gözükmektedir. Bu yöntemlerin ardından sirasıyla alan yazın derleme çalışmaları ve karma yöntem kullanıldığı sonuçlarına ulaşılmıştır. M-öğrenme üzerine yapılan değerlendirme çalışmalarında, en çok nitel yöntemin kullanıldığ 1 nicel ve karma yöntemin tercih edilmediği, m-öğrenme teknolojileri üzerine yapılan çalışmalarda, en çok alan yazın derlemesi yapıldığı nicel ve karma yöntemin tercih edilmediği, m-öğrenme üzerine proje geliştirme çalışmalarında ise en s1k nitel yöntem kullanıldığı nicel ve alan yazın derleme yönteminin tercih edilmediği gözükmektedir. Ayrıca m-öğrenme hakkında görüşler, m-öğrenme teknolojileri, m-öğrenme proje çalışması ve m-öğrenme üzerine değerlendirme çalışmalarında nicel yöntem kullanılmadığ $1, \mathrm{~m}$ öğrenmeye yönelik tutum belirleme, m-öğrenmeye yönelik beklenti, m-öğrenmenin beceriye etkisi, möğrenmeye yönelik ölçek çalışmalarında ise nicel yöntemin benimsenip diğer yöntemlerin kullanılmadığı sonuçlarına ulaşılmıştır.

Araştırmada yer alan veri toplama araçlarının yöntemlere göre dağılımını gösteren veriler Tablo 4'te verilmiş̧ir.

Tablo 4. Mobil öğrenme çalışmalarının veri toplama yöntemlerinin araştırma yöntemlerine göre dağılımı

\begin{tabular}{|c|c|c|c|c|c|c|}
\hline \multirow[b]{2}{*}{ Veri Toplama Araçları } & \multicolumn{4}{|c|}{ Yöntem } & \multicolumn{2}{|c|}{ Toplam } \\
\hline & Nicel & Nitel & Karma & $\begin{array}{l}\text { Alan Yazın } \\
\text { Derlemesi }\end{array}$ & $\mathbf{N}$ & $\%$ \\
\hline Gözlem & & 1 & & & 1 & 4,2 \\
\hline Görüşme & & 1 & 1 & & 2 & 8,3 \\
\hline Başarı Testi & & & & & $\mathbf{0}$ & $\mathbf{0 , 0}$ \\
\hline $\begin{array}{l}\text { Tutum, algı, kişilik veya Yetenek } \\
\text { testleri }\end{array}$ & & & & & 0 & $\mathbf{0 , 0}$ \\
\hline Anket & 7 & 1 & 1 & & 9 & 37,5 \\
\hline Döküman & & & & & $\mathbf{0}$ & $\mathbf{0 , 0}$ \\
\hline Alternatif Araçlar & & & & & $\mathbf{0}$ & 0,0 \\
\hline Diğer & 1 & 7 & & 4 & 12 & $\mathbf{5 0 , 0}$ \\
\hline TOPLAM & 8 & 10 & 2 & 4 & 24 & 100 \\
\hline
\end{tabular}

Tablo 4'te verilen bulgular incelendiğinde yapılan araştırmalarda veri toplama aracı olarak en sık diğer seçeneği kullanıldığı gözükmektedir. İncelenen çalışmalar ele alındığı zaman analiz yapmak, öneri sunmak ve değerlendirme yapmak amacı ile yapılan araştırmalarda makale ve geliştirilen möğrenme platformlarının veri toplama aracı olarak kullanıldığı gözlemlenmiştir. Yani diğer seçeneğinde makale ve kullanılan bu platformlar yer almaktadır. Diğer açıdan tabloya bakıldığında ise en sık kullanılan veri toplama aracı olarak anket, görüşme ve gözlem kullanıldığı sonuçları elde edilmiştir. Ayrıca veri toplama aracı olarak başarı, tutum, algı, kişilik veya yetenek testlerinin, doküman ve alternatif araçların tercih edilmediği gözükmektedir. Nicel araştırma yöntemlerinde en sık kullanılan veri toplama aracı olarak anket ve diğer seçeneğinin yer aldığı, nitel araştırma yöntemlerinde en sık kullanılan veri toplama aracı olarak diğer seçeneği ve anket, görüşme, gözlem kullanıldığı, karma yöntemde ise anket ve görüşme kullanıldığı sonuçlarına rastlanmıştır. Alan yazın derleme yönteminde ise sadece diğer seçeneği kullanıldığ gözükmektedir.

Araştırmada yer alan örneklem düzeylerinin dağılımını gösteren veriler Tablo 5 'te verilmiştir.

Tablo 5. Yaygın olarak seçilen örneklem düzeylerinin dağılımı

\begin{tabular}{lcc}
\hline Örneklem Düzeyi & $\mathbf{N}$ & $\mathbf{\%}$ \\
\hline Okul Öncesi & 0 & 0 \\
İlköğretim (1-5) & 0 & 0 \\
İlköğretim (6-8) & 0 & 0 \\
Ortaöğretim (9-12) & 0 & 0 \\
Lisans (Ĕ̆itim Fak.) & 6 & 25 \\
Lisans (Diğgr) & 2 & 8 \\
Lisansüstü (Master-Doktora) & 1 & 4 \\
Öğretmenler & 0 & 0 \\
Öğretim elemanları & 2 & 8
\end{tabular}


Veliler

Yöneticiler

$0 \quad 0$

Diğer

0

13

0

TOPLAM

$24 \quad 100 \%$

Tablo 5'e bakıldığında incelenen çalışmalarda örneklem düzeyi olarak en çok diğer seçeneği kullanılmıştır. Diğer seçeneğine çalışmalar göz önünde bulundurularak bakıldığında ise makaleler, möğrenme için geliştirilmiş platformlar ve meslek yüksekokulunda okuyan öğrenciler seçeneklerinin oluşturduğu gözükmektedir. Tabloya bakıldığında en sık kullanılan örneklem düzeyini eğitim fakültesinde okuyan lisans öğrencilerinin, diğer fakültelerdeki lisans öğrencilerinin, lisansüstü öğrencilerinin ve öğretim elemanlarının oluşturduğu, diğer örneklem düzeylerinin ise tercih edilmediği bulgularına rastlanmıştır.

Araştırmada yer alan örneklem sayılarının dağılımını gösteren veriler Tablo 6'da sunulmuştur.

Tablo 6. Yaygın olarak seçilen örneklem sayılarının dağılımı

\begin{tabular}{lcc}
\hline Örneklem Sayı Aralı̆̆ & $\mathbf{N}$ & $\mathbf{\%}$ \\
\hline $1-10$ arası & 2 & 8,3 \\
$11-30$ & 10 & 41,7 \\
$31-100$ & 5 & 20,8 \\
$101-300$ & 3 & 12,5 \\
$301-1000$ & 4 & 16,7 \\
1000 'den fazla & 0 & 0,0 \\
\hline TOPLAM & $\mathbf{2 4}$ & $\mathbf{1 0 0}$ \\
\hline
\end{tabular}

Tablo 6 incelendiğinde örneklem için seçilen sayı aralığında en yaygın olarak kullanılan aralığın 11-30 aralığ 1 olduğu gözlemlenmektedir. En yaygın olarak kullanılan aralıkların sırası ile 31-100, 3011000, 101-300, 1-10 arasında olduğu 1000'den fazla olan aralığın ise hiç tercih edilmediği bulgularına ulaşılmıştır.

Araştırmada yer alan örneklem sayılarının araştırma yöntemlerine göre dağılımı gösteren veriler Tablo 7'de verilmiştir.

Tablo 7. Mobil öğrenme araştırmalarının yöntemlerine göre örneklem sayıları

\begin{tabular}{lcccccc}
\hline \multirow{2}{*}{ Örneklem Sayı Aralı̆̆ } & & \multicolumn{3}{c}{ Yöntem } & \multicolumn{2}{c}{ Toplam } \\
& Nicel & Nitel & Karma & Alan Yazın Derlemesi & N & \% \\
\hline $1-10$ arası & 2 & 7 & & 2 & 2 & 8,3 \\
$11-30$ & 1 & 2 & 1 & 1 & 10 & 41,7 \\
$31-100$ & 1 & 1 & 1 & & 5 & 20,8 \\
$101-300$ & 4 & & & & 3 & 12,5 \\
$301-1000$ & & & & & 0 & 0,0 \\
1000 'den fazla & $\mathbf{8}$ & $\mathbf{1 0}$ & $\mathbf{2}$ & $\mathbf{4}$ & $\mathbf{2 4}$ & $\mathbf{1 0 0}$ \\
\hline TOPLAM & & & & & &
\end{tabular}

Tablo 7'ye bakıldığında nicel araştırma yöntemi kullanılan çalışmalarda en çok 301-1000 sayı aralığında örneklem kullanıldığ1, bu aralığ sırasıyla 11-30, 31-100 ve 101-300 aralığının takip ettiği, 1-10 ve 1000 'den fazla aralığının ise kullanılmadığı gözlemlenmiştir. Nitel araştırma yöntemi kullanılan çalışmalarda en çok 11-30 aralığının tercih edildiği, bu aralığı sırasıyla 31-100 ve 101-300 aralığının takip ettiği, 1-10, 301-1000 ve 1000'den fazla olan aralığın ise kullanılmadığ gözlemlenmiştir. Karma yöntemde 31-100 ve 101-300 aralığının kullanıldığı diğer aralıktaki örneklem sayılarının kullanılmadığ gözlemlenmiştir. Alan yazın derlemesinde ise 1-10, 11-30, 31-100 aralıklarının kullanıldığı diğer aralıklarının kullanılmadığı bulgularına rastlanmıştır. 


\section{TARTIŞMA ve SONUÇ}

Bu çalışmada 2010-2017 yılının Ocak, Şubat ve Mart ayı içerisindeki Google Scholar, Academia.edu ve Dergipark adresleri üzerinde mobil öğrenme anahtar kelimesi ile aranmış, dergilerde yayımlanan makalelerden oluşan toplam 24 m-öğrenme çalışması araştırmaların; hangi dergilerde yayınlandığı, konularının neler olduğu, yıllara göre dağılımları, kullanılan yöntemler, veri toplama araçları ve örneklem dağılımlarını ele alarak incelenmiştir. Yapılan içerik analizi sonuçlarına göre ise şu bulgular elde edilmiştir:

M-öğrenme üzerine yapılan çalışmaların Eğitim Teknolojisi Kuram ve Uygulama Dergisi, Akademik Bilişim Konferansları, Açıköğretim Uygulamaları ve Araştırmaları Dergisi'nde yoğun olarak yayınlandığı belirlenmiştir. Bu dergilerin tercih edilme nedenlerinin uzun süredir hizmet vererek isimlerini duyurmuş olmaları, akademik bilişim konferansının ise her sene geniş kapsamlı konuları ele alarak fazla çalışma sunuyor olmaları düşünülmüştür. Yapılan çalışmaların konularına bakıldığında ise m-öğrenme üzerine değerlendirme yapma, m-öğrenme teknolojilerinin neler olduğu ve m-öğrenme üzerine proje geliştirme çalışmalarının diğer konulara göre sıklık gösterdiği bulgularına ulaşılmıştır. $\mathrm{Bu}$ konuların tercih edilme nedeni mobil cihazların eğitim alanına girmesi ile birlikte m-öğrenme için öğrenme platformlarının geliştirilmesi için duyulan ihtiyaçtan kaynaklanıyor olabileceği düşünülmektedir. Nitekim Çakır (2011) m-öğrenmeye yönelik yazılım geliştirdiği bir çalışmasında ülkemizde cep telefonlara olan ilginin çok olmasına rağmen çeşitli nedenler ve m-öğrenmeye yönelik algıların düşük olmasından kaynaklı m-öğrenmeye yönelik uygulamaların henüz yaygınlaşamadığını ifade etmişlerdir. Ayrıca Kuşkonmaz (2011) da akademik anlamdaki çalışmaların özel şirketlerin çalışmalarından daha geride kaldığını ifade ederek m-öğrenmeye yönelik akademik anlamda yapılacak olan çalışmaların henüz yeterli olmadığına dikkat çekmiştir. Bu ifadeler m-öğrenme için öğrenme platformlarının geliştirilmesinde var olan eksiklik ve ihtiyaç duyulmasından kaynaklı olarak bu konulara yönelinmesini destekler niteliktedir.

Yapılan araştırmalarda kullanılan veri toplama araçları ele alındığında yayınlanmış makale ve geliştirilen m-öğrenme platformlarının sık kullanıldığı gözlemlenmiştir. Bunun nedeni de son zamanlarda m-öğrenme platformları geliştirmek ve bu geliştirilen platformların hedef kitle üzerinde ne kadar etkili olduğu, platformda ki eksik ve hataların neler olduğunu belirleyerek daha etkili ve kullanılabilir bir platform sunmak olabilir. Nitekim Doğan ve Seferoğlu'da (2015) bu durumu şu sözler ile ifade etmişlerdir: Öncelikli olarak mobil cihazlara uygun içeriklerin ve uygulamaların geliştirilmesi mobil cihazların eğitim-öğretim süreçlerinde etkili bir şekilde kullanılabilmeleri için gereklidir. Ayrıca diğer veri toplama araçlarına bakıldığında anket, görüşme ve gözlem araçlarının çok sık tercih edilmesi de diğer elde edilen bulgular arasındadır. Solmaz ve Gökçearslan'ın (2016), m-öğrenme üzerine yapılmış lisansüstü tezlere yönelik içerik analizi çalışmalarında en çok tercih edilen veri toplama araçları olarak araştırmacı günlüğü, e-postalar, kontrol listesi, değerlendirme formu, sistem logları, elektronik mesajlar, günlükler, sınıflama formu, kullanılabilirlik testleri ve veri tabanı kayıtları gibi diğer seçeneği altında toplanan araçlar çıkmıştır. Diğer seçeneğinden sonra en çok kullanılan veri toplama tekniğinin ise anket olduğu bulguları, bu çalışmadaki bulguları destekler niteliktedir.

M-öğrenme üzerine en çok çalışmanın 2015 ve 2016 yıllarında gerçekleştirildiği ve örneklem olarak alınan sitelerde 2014 yılına ait bir çalışmanın bulunamadığı elde edilen diğer bulgulardandır. Solmaz ve Gökçearslan'ın (2016), 2005-2015 yılları arasındaki m-öğrenme üzerine yapılmış lisansüstü tezlere yönelik analiz çalışmasında 2010 yılından sonra çalışmaların sayısının arttığı sonuçlarına ulaşılmıştır. En çok lisansüstü çalışmanın 2014 yılında yapılmış olması bu araştırmalardaki bulgu ile ters düşmektedir. Bunun nedeni bu araştırmada seçilen örneklemin farklı olmasından kaynaklanıyor olabileceği düşünülmektedir. M-öğrenme üzerine yapılan her iki çalışmada da son yıllara doğru artış olduğu bulguları ise birbirini destekler niteliktedir. Bu artış nedeninin mobil teknoloji kullanımındaki artışa ve mobil teknolojilerinin öğrenme sürecinde sağladıkları avantajların farkına varılmasından kaynaklanmış olabileceği düşünülmektedir. Çünkü mobil teknolojilerin bağımsız öğrenme ortamları oluştururken öğrencilerin sınıfta veya sınıf dışında ders ile ilgili fikir ve düşüncelerini ortaya çıkarmasında katkıda bulunduğu fikri gitgide yaygınlaşmaktadır (Furio vd.,2015; Gerger, 2014). Ayrıca TÜİK verilerine bakıldığında hanedeki kişilerin cep telefonu/ akıllı telefon sahibi olma oranlarının her 
geçen sene artış gösterdiği ve 2017 yılı itibariyle bu oranın \%97,8 gibi ciddi oranlara ulaştığı verileri bu çıkarımı destekler niteliktedir (TÜíK, 2017).

M-öğrenme çalışmalarında benimsenen yöntemlere bakıldığında nitel ve nicel yöntemlerin sık kullanıldığı gözlemlenmiştir. Birden çok yöntemi içine alarak daha detaylı ve derinlemesine bir inceleme yapma gereği oluşturan alan yazın derleme çalışmaları ve karma yöntemin zaman açısından araştırmacıları kısıtlayacağı ve daha az tercih etmelerine sebep olabileceği düşünülmüştür. Ayrıca konular ve seçilen yöntemler karşılaştırıldığında; m-öğrenme üzerine yapılan değerlendirme çalışmalarında, en çok nitel yöntemin kullanıldığı nicel ve karma yöntemin tercih edilmediği, möğrenme teknolojileri üzerine yapılan çalışmalarda, en çok alan yazın derlemesi yapıldığı nicel ve karma yöntemin tercih edilmediği, m-öğrenme üzerine proje geliştirme çalışmalarında ise en sık nitel yöntem kullanıldığı nicel ve alan yazın derleme yönteminin tercih edilmediği bulgularına ulaşılmıştır. M-öğrenmeye yönelik tutum belirleme, m-öğrenmeye yönelik beklenti, m-öğrenmenin beceriye etkisi, m-öğrenmeye yönelik ölçek çalışmalarında ise nicel yöntemin benimsenip diğer yöntemlerin kullanılmadığı sonuçlarına ulaşılmıştır. Örneklem düzeyi incelendiğinde en çok makaleler, m-öğrenme için geliştirilmiş platformların ele alındığı ve meslek yüksekokulunda okuyan öğrencilerin en sık tercih edilenler olduğu, eğitim fakültesinde okuyan lisans öğrencilerinin, diğer fakültelerdeki lisans öğrencilerinin, lisansüstü öğrencilerinin ve öğretim elemanlarının da örneklem düzeyi olarak tercih edildiği belirlenmiştir. Henüz mobil cihazların okul öncesi, ilköğretim ve ortaöğretim düzeyinde ki okullarda yeterince yaygınlaşmamış olmasının örneklem düzeyi olarak tercih edilmemeye sebep olabileceği düşünülmektedir. Örneklem için seçilen sayı aralığında ise en yaygın olarak kullanılan aralığın 11-30 aralığı olduğu bulgularına rastlanmıştır. Ayrıca 31-100, 301-1000, 101-300, 1-10 aralıkları da örneklem için seçilen aralıklarda sırası ile en yaygın olarak kullanılan aralıklardır. Örneklemlerde 1000 'den fazla olan aralığın ise hiç tercih edilmediği de diğer bulgular arasındadır. Yapılan araştırmalarda ki bulgular bu bulguyu destekler niteliktedir. Nitekim Selçuk ve Palancı (2014) tarafından yapılan bir içerik analizi çalışmasında da araştırma sonucuna göre, 1000'den fazla örneklem sayısını oluşturan araştırmaların diğerlerine göre daha az olduğu, Solmaz ve Gökçearslan'ın (2016), yaptığı çalışmada ise 1000 'den fazla örneklem sayısını oluşturan araştırmaya rastlanılmadığı sonuçları bulunmuştur. Çalışmalarda kullanılan yöntem ve örneklem aralıkları karşılaş̧ırıldığında ise, nicel araştırma yöntemi kullanılan çalışmalarda en çok 301-1000 sayı aralığında örneklem kullanıldığı 1-10 ve 1000 'den fazla aralığının ise kullanılmadığ 1 gözlemlenmiştir. Nitel araştırma yöntemi kullanılan çalışmalarda en çok 11-30 aralığının tercih edildiği, 1-10, 301-1000 ve 1000'den fazla olan aralığın ise kullanılmadığ 1 gözlemlenmiştir. Karma yöntemde 31-100 ve 101-300 aralığının kullanıldığı diğer aralıkta ki örneklem sayılarının kullanılmadığı gözlemlenmiştir. Alan yazın derlemesinde ise 1-10, 1130, 31-100 aralıklarının kullanıldığı diğer aralıklarının kullanılmadığı bulguları da araştırmada elde edilen bulgulardır.

Sonuç olarak bu çalışmada 2010-2017 yılları arasında Türkiye'de yapılmış m-öğrenme çalışmaları çeşitli kategorilerde incelenmiştir. Çalışmada elde edilen bulguların gelecekte yapılacak olan araştırmalara katkı sağlaması açısından önemli olacağı düşünülmektedir. 


\section{KAYNAKLAR}

Ağca, R. K., \& Bağc1, H. (2013). Eğitimde mobil araçların kullanımına ilişkin öğrenci görüşleri (Students views of mobile tools usage in education). Ĕ̈itim ve Ö̆retim Araştırmaları Dergisi, 2, 295-302.

Akpınar, Y. (2005). Bilgisayar destekli eğitimde uygulamalar. Ankara: Anı Yayınevi.

Arıcı, N., \& Bal, Y. (2011). Mobil öğrenme materyali hazırlama süreci. Internatıonal Journal Of Informatıcs Technologles, 4(1).

Bal, Y. (2010). Mesleki ortä̈ğretimde M-öğrenme materyallerinin öğrenmeye katkısının incelenmesi. Yüksek Lisans Tezi, Gazi Üniversitesi Bilişim Enstitüsü, Ankara.

Bauer, M. W. (2003). Classical content analysis: A review. In M. W. Bauer \& G. Gaskell (Eds). Qualitative researching with text, image and sound (131-151). London: Sage Publication.

Bozkurt, D. Ö. A. (2015). Mobil öğrenme: Her zaman, her yerde kesintisiz öğrenme deneyimi. Açıköğretim Uygulamaları ve Araștırmaları Dergisi, 1(2).

Çakır, H. (2011). Mobil öğrenmeye ilişkin bir yazılım geliştirme ve değerlendirme. Çukurova Üniversitesi Ĕgitim Fakültesi Dergisi, 2(40), 1-9.

Çelik, A. (2013). M-öğrenme tutum ölçeği: Geçerlik ve güvenirlik analizleri. Journal of Research in Education and Teaching, 2(4), 172-185.

Delil, S. (2015). Mobil cihazların bir eğitim materyali olarak kullanımı: Doğru tasarlanmış mobil eğitim uygulamalarının öğrenime katkısı. International Journal of Social Sciences and Education Research, 3(1).

Demir, K., \& Akpınar, E. (2016). Mobil öğrenmeye yönelik tutum ölçeği geliştirme çalışması. Eğitim Teknolojisi Kuram ve Uygulama, 6(1).

Doğan, D., \& Seferoğlu, S. S. (2015). Mobil cihazlar ve eğitimde dijital dönüşüm. Eğitim Teknolojileri Okumalarl, 541-545.

Ekren, Ö. G. G., \& Kesim, M. (2016). Mobil iletişim teknolojilerindeki gelişmeler ve mobil öğrenme. Açı̌̈̈ğretim Uygulamaları ve Araștırmaları Dergisi, 36.

Elçiçek, M., \& Bahçeci, F. (2015). Meslek yüksekokulu öğrencilerinin mobil öğrenmeye yönelik tutumlarının incelenmesi. Sakarya Üniversitesi Ĕ̆itim Fakültesi Dergisi, (30), 17-33.

Furio, D., Juan, M. C., Seguí, I., \& Vivo, R. (2015). Mobile learning vs. Traditional classroom lessons: a comparative study. Journal of Computer Assisted Learning, 31(3), 189-201.

Gerger, K. (2014). 1:1 tablet technology implementation in the Manhattan Beach Unified School District: A case study. Doktora Tezi, California State University, Long Beach, ABD.

Gökçearslan, Ş., Solmaz, E., \& Kukul, V. (2017). Mobil öğrenmeye yönelik hazırbulunuşluk ölçeği: bir uyarlama çalışması. Eğitim Teknolojisi Kuram ve Uygulama Dergisi,7(1).

Gülseçen, S., Gürsul, F., Bayrakdar, B., Çilengir, S., \& Canım, S. (2010). Yeni nesil mobil öğrenme aracı: Podcast. XII. Akademik Bilişsim Konferansı Bildirileri, Muğla Üniversitesi, 10-12.

Güneş, F., Çukurbaşı, B., \& Işık, A. (2015). Bilgi teknolojisinden beyin teknolojisine: mobil öğrenme projesinin değerlendirilmesi. Bartın Üniversitesi Eğitim Fakültesi Dergisi,11-18.

Günes, F., Isık, A. D., \& Çukurbası, B. (2015). Mobil ögrenme uygulamalarinin ögretmen adaylarinin tablet bilgisayar kullanma becerilerine etkisi*/the effect of mobile learning applications using tablet computer skills of candidates teachers. Bartın Üniversitesi Eğitim Fakültesi Dergisi, 1.

Güzelyazıc1, Ö., Dönmez, B., Kurtuluş, G., \& Hacıosmanoğlu, Ö. (2014). Yeni Yüzyil Üniversitesinde Mobil Öğrenme. Ejovoc (Electronic Journal of Vocational Colleges), 4(2).

Hahn, J. (2008). Mobile learning for the twenty-first century librarian. Reference Services Review, 36(3), $272-$ 288. doi: $10.1108 / 00907320810895369$

Işık, A. D. (2016). Mobil öğrenmeden sınırsız öğrenmeye. Sinırsız Eğitim ve Araştırma Dergisi, 1(1).

Işık, A. H., Özkaraca, O., \& Güler, İ. (2011). Mobil öğrenme ve podcast. XII. Akademik Bilişsim Konferansı Bildirileri, 861-866.

Karataş, E. (2016). "Mobil Uygulama Geliştirme" lisansüstü dersine ilişkin öğrenci görüşleri. Eğitim Teknolojisi Kuram ve Uygulama, 6(1).

Keskin, N. Ö. (2010). Mobil öğrenme teknolojileri ve araçları. Akademik Bilişsim, 10, 490.

Keskin, N. Ö., \& Kılınç, A. G. H. (2015). Mobil öğrenme uygulamalarına yönelik geliştirme platformlarının karşılaştırılması ve örnek uygulamalar. Açıöğretim Uygulamaları ve Araştırmaları Dergisi, 1(3).

Kıc1, D. (2010). Üniversite öğrencilerinin mobil öğrenmenin üniversite eğitimindeki etkisi konusundaki beklentileri üzerine bir araştırma. In International Conference On New Trends in Education and Their Implications, Antalya, Turkey, 565-572.

Korkmaz, M. (2010). Probleme dayalı mobil öğrenmenin öğrencilerin akademik başarılarına etkisi. Yüksek Lisans Tezi, İstanbul Üniversitesi, İstanbul.

Kuşkonmaz, H. (2011). İlköğretim okullarındaki öğretmenlerin mobil ögrenmeye yönelik algı düzeylerinin belirlenmesi. Yayınlanmamış Yüksek Lisans Tezi, Bahçeşehir Üniversitesi, İstanbul.

Menzi, N., Önal, N., \& Çalışkan, E. (2012). Mobil teknolojilerin eğitim amaçlı kullanımına yönelik akademisyen görüşlerinin teknoloji kabul modeli çerçevesinde incelenmesi. Ege Eğitim Dergisi, 13(1). 
Niazi, R. (2007). Desing and implementation of a device-independent platform for mobile learning. Yayınlanmamış Yüksek Lisans Tezi, The University of Guelph, Canada.

Özarslan, M., Kubat, B., \& Bay, Ö. F. (2007). Uzaktan eğitim için Entegre Ofis Dersi’nin Web tabanlı içeriğinin geliştirilmesi ve üretilmesi. Akademik Bilişim'07, 31.

Parsons, D., \& Ryu, H. (2006). A framework for assessing the quality of mobile learning. In Proceedings of the International Conference for Process Improvement, Research and Education, 17-27.

Quinn, C. (2000). Line Zine. Retrieved june 16, Tuesday, 2014, from http://www.linezine.com/2.1/features/cqmmwiyp.htm.

Raua, P.-L. P., Gaoa, Q., \& Wub, L.-M. (2008). Using mobile communication technology in high school education: motivation, pressure, and learning performance. Computers \& Education, 50, 1-22.

Sağır, F., \& Göksu, H. (2015). Öğretmen adaylarının mobil eğitim uygulamalarına yönelik tutumları: KKTC örneği. VI. Ĕ̆itim Yönetimi Forumu, 44-50.

Salanda, J. (2011). Fundamentals of qualitative research: Understanding qualitative research. Oxford University Press, Newyork.

Silverman, D. (2001). Interpreting qualitative data: Methods for analysing talk, text and interaction. London: SAGE Publication.

Selçuk, Z., Palancı, M., Kandemir, M., \& Dündar, H. (2014). Eğitim ve bilim dergisinde yayınlanan araştırmaların eğilimleri: İçerik analizi. Eğitim ve Bilim, 39(173).

Siemens, G. (2002). Instructional design in elearning. Retrieved January, 21, 2013.

Solmaz, E., \& Gökçearslan, Ş. (2016). Mobil öğrenme: Lisansüstü tezlere yönelik bir içerik analizi çalışması. 10th International Computer and Instructional Technologies Symposium (ICITS), Recep Tayyyip Erdoğan Üniversitesi, Rize-Türkiye.

Torun, F., \& Dargut, T. (2015). Mobil öğrenme ortamlarında ters yüz sınıf modelinin gerçekleştirilebilirliği üzerine bir öneri. Adnan Menderes Üniversitesi Ĕ̆itim Fakültesi Eğitim Bilimleri Dergisi, 6(2).

Türkiye İstatistik Kurumu (2017). Hanehalkı Bilişim Teknolojileri Kullanım Araştırması. 08.03.2018 tarihinde http://www.tuik.gov.tr/PreTablo.do?alt_id=1028 sayfasından erişilmiştir.

Trifonova, A. (2003). Mobile learning-Review of the literature. (Rapor No: DIT-03-009). Trento Universitesi, Bilgi ve İletişim Teknolojileri Bolumu.

Yıldırım, A., \& Şimşek, H. (2011). Sosyal bilimlerde nitel araştırma yöntemleri (14. baskı). Ankara: Seçkin Yayıncilık.

Y1lmaz, Y. (2011). Mobil ögrenmeye yönelik lisansüstü ögrencilerinin ve ögretim elemanlarının farkındalık düzeylerinin araştırılması. Yayınlanmamış Yüksek Lisans Tezi. Dokuz Eylül Üniversitesi, İzmir.

Yokuş, G. (2016). Eğitim fakültesi ögrencilerinin mobil ögrenmeye ilişkin görüşlerinin incelenmesi ve eğitim bilimleri alanına yönelik mobil uygulama geliştirme çalışması: Mobil akademi. Yayımlanmamış Yüksek Lisans Tezi. Mersin Üniversitesi, Mersin.

Winters, N. (2006). What is mobile learning?. In Big Issues in Mobile Learning (Ed. Mike Sharples), 4-8. UK: University of Nottingham.

Winters, N. (2007). What is mobile learning. Big issues in mobile learning, 7-11. Erişim tarihi:20.04.2016, http://www.cin.ufpe.br/ mlearning/intranet/mlearning/Big\%20Issues\%20in\%20Mobile\%20 Learning.pdf\#page $=5$

Wyne, M. F. (2015). Merging mobile learning into traditional education, 2013- 2016. The International Conference on E-Learning in the Workplace’te sunulmuştur. New York: Amerika Birleşik Devletleri. 